\title{
PEMBELAJARAN SASTRA MULTIMODAL
}

\author{
Mochamad Bayu Firmansyah \\ Universitas PGRI Wiranegara
}

\section{A. Landasan Filosofis dan Orientasi Teoritis}

Pembelajaran sastra multimodal mengacu pada landasan filosofis kontruktivisme. Kontruktivisme merupakan sudut pandang filosofis tentang sifat pengetahuan dan juga sikap ontologis (Wadsworth, 1996). Fokus pandangan konstruktivisme terhadap bagaimana manusia membuat makna dalam kaitannya dengan interaksi antara pengalaman dan ide-ide. Pandangan filsafat kontruktivisme cenderung pada pembentukan pribadi untuk memperoleh informasi yang dipengaruhi oleh sosial. Secara garis besar, prinsip-prinsip konstruktivisme dalam pembelajaran (Suparno, 1997), yakni: (a). pengetahuan dibangun oleh peserta didik sendiri, baik secara personal maupun sosial, (b). pengetahuan tidak dipindahkan dari pendidik ke peserta didik, kecuali dengan keaktifan siswa sendiri untuk bernalar, (c). peserta didik aktif mengkontruksi secara terus menerus, sehingga terjadi perubahan konsep menuju ke konsep yang lebih rinci, lengkap, serta sesuai dengan konsep ilmiah, (d). pendidik berperan membantu menyediakan sarana dan situasi agar proses konstruksi peserta didik berjalan mulus.

Pandangan konstruktivistik dilandasi oleh teori Piaget (2013) tentang skema, asimilasi, akomodasi, dan equilibrasi, konsep Zone of Proximal Development (ZPD) dari Vygotsky (1998), teori Bruner (2009) tentang discovery learning, teori Ausubel (1963) tentang belajar bermakna, dan interaksionisme semiotik. Berikut ini deskripsi beberapa teori yang melandasi pendekatan konstruktivistik, yakni (a) Piaget; Skema merupakan struktur mental atau kognitif seseorang secara intelektual beradaptasi dan mengkoordinasi lingkungan sekitarnya. Asimilasi merupakan proses kognitif yang dengannya seseorang mengintegrasikan persepsi, konsep, atau pengalaman baru ke dalam skema atau pola yang sudah ada dalam pikirannya. Akomodasi, seseorang dalam menghadapi ransangan atau pengalaman yang baru, tidak dapat mengasimilasikan pengalaman yang baru itu dengan skema yang telah ia punyai. Equilibrasi merupakan perkembangan intelektual seseorang diperlukan keseimbangan antara asimilasi dengan akomodasi, (b) Vygotsky, Zone of Proximal Development (ZPD) merupakan perkembangan psikologis dan pembelajaran tertanam secara sosial, dan untuk memahaminya harus menganalisis masyarakat sekitar dan hubungan-hubungan sosialnya, (c) Bruner, Discovery Learning merupakan pendekatan pembelajaran yang memungkinkan siswa menggunakan informasi untuk mengkonstruksi pemahamannya sendiri, (d) Ausabel, Belajar 
Bermakna merupakan proses mengkaitkan informasi baru pada konsep-konsep relevan yang terdapat dalam struktur kognitif seseorang, dan Interaksional Semiotik merupakan pola-pola kegiatan situasional praktis.

Pembelajaran sastra multimodal menggunakan pandangan konstruktivisme Ausabel. Belajar bermakna yang kemudian disebut dengan struktur kognitif merupakan struktur organisasional yang terdapat dalam ingatan seseorang yang selanjutnya terintegrasi melalui unsur-unsur pengetahuan yang terpisah ke dalam suatu unit konseptual (Ausabel, 1963). Persyaratan dalam pembelajaran bermakna, yakni: (a). Pengaturan awal (Advance organizer). Pengaturan awal berisi tentang konsep-konsep atau ide-ide yang diberikan kepada mahasiswa jauh sebelum materi pelajaran yang sesungguhnya diberikan, (b). Progressive differentiation. Pengembangan konsep berlangsung baik jika dimulai dengan menjelaskan terlebih dahulu halhal umum terus sampai kepada hal-hal khusus secara rinci disertai dengan contoh-contoh, (c). Rekonsiliasi integratif. Menjelaskan dan menunjukkan secara jelas perbedaan dan persamaan bahan ajar yang baru dengan bahan ajar yang telah dijelaskan terlebih dahulu atau yang telah dikuasai mahasiswa, (d). Konsolidasi (consolidation). Memberikan pemantapan atas bahan ajar yang telah diberikan untuk memudahkan mahasiswa memahami dan mempelajari bahan ajar selanjutnya. Gagasan belajar bermakna (meaningfull learning) Ausabel lebih pada penekanan proses untuk mengaitkan informasi baru dengan konsep-konsep yang saling terkait dalam struktur kognitif seseorang (Ausabel, 1963). Sebelum menerapkan dalam pembelajaran, pendidik disarankan untuk mengetahui terlebih dahulu kondisi awal peserta didik. Hal ini sejalan dengan pandangan bahwa ada satu faktor yang sangat mempengaruhi belajar, yaitu pengetahuan yang telah diterima peserta didik.

Pemilihan pembelajaran sastra multimodal sebagai upaya untuk mengembangkan kompetensi literasi multimodal mahasiswa. Hal tersebut sejalan dengan Era revolusi industri 4.0 yang menuntut mahasiswa untuk mampu menguasai kompetensi tidak hanya membaca, menulis dan matematika sebagai modal dasar berkiprah di masyarakat, melainkan literasi baru yakni, literasi data, literasi teknologi dan literasi manusia (Nasir, 2018). Kompetensi tersebut mengarah pada profil lulusan dan capaian pembelajaran yang terbagi dalam kompetensi ilmu pengetahuan, kompetensi kerja khusus, kompetensi kerja umum, dan kompetensi sikap yang terdapat dalam perguruan tinggi penyelenggara. Penentuan kompetensi berdasarkan kurikulum pendidikan tinggi yang diatur dalam UU. No. 12/2012 tentang pendidikan tinggi pasal 35. Pengembangan kompetensi berdasarkan kesepakatan forum prodi sejenis atau pengelola prodi serta mengacu pada SN Dikti dan KKNI terintegrasi. Adapun kompetensi level 6 atau setara dengan lulusan S1 (Tinggi, 2014), yakni: (a). Mampu mengaplikasikan bidang keahlian dan 
memanfaatkan ipteks pada bidangnya dalam penyelesaian masalah serta mampu beradaptasi terhadap situasi yang dihadapi, (b). menguasai konsep teoritis bidang pengetahuan tertentu secara umum dan konsep teoritis bagian khusus dalam bidang pengetahuan tersebut secara mendalam, serta mampu memformulasikan penyelesaian masalah prosedural, (c). mampu mengambil keputusan yang tepat berdasarkan analisis informasi dan data, dan mampu memberikan petunjuk dalam memilih berbagai alternatif solusi secara mandiri dan kelompok, (d). bertanggung jawab pada pekerjaan sendiri dan dapat diberi tanggung jawab atas pencapaian hasil kerja organisasi.

Sejalan dengan hal tersebut, pemilihan pembelajaran sastra multimodal cukup beralasan sebagai upaya untuk mengembangkan kompetensi literasi multimodal mahasiswa. Melalui pembelajaran sastra multimodal dapat meningkatkan kompetensi komunikatif mahasiswa, pemahaman budaya, serta sikap terhadap bahasa (Coccetta, 2018; Kennedy, 2014; Freyn \& Ed, 2017). Pembelajaran sastra multimodal dikembangkan melalui teori sistem fungsi bahasa (Halliday, 1977, 1978; Halliday \& Hasan, 1985). Menurut pandangan Halliday bahasa dipandang sebagai semiotika sosial. Melalui bentuk bahasa (encode) dapat merepresentasikan dunia yang dikonstruksi secara sosial. Penekanannya pada konteks sosial bahasa, yakni fungsi sosial yang menentukan bentuk bahasa dan bagaimana perkembangannya. Selanjutnya literasi multimodal diarahkan pada berbagai sumber teks yang dapat memproduksi makna. Literasi multimodal merupakan upaya memahami berbagai cara representasi pengetahuan dan pembuatan makna (Jewitt dan Kress, 2003). Fokus literasi multimodal pada desain wacana dengan menyelidiki sumbangsih dari berbagai sumber semiotik (verbal, visual, dan gerak) yang dikerahkan melalui berbagai modalitas serta interaksi dan integrasi dalam proses koherensi teks. Literasi multimodal mempertimbangkan bagaimana pilihan linguistik dan visual memenuhi tujuan teks, audien dan konteks, serta bagaimana pilihan-pilihan itu bekerja bersama dalam organisasi dan pengembangan informasi dan ide (Lim \& Tan, 2017). Literasi multimodal dalam konteks pembelajaran menggunakan pandangan konstruktivisme. Dalam dimensi pembelajaran literasi multimodal, peserta didik dituntut peka terhadap potensi makna dan pilihan yang diberikan dalam produksi teks (O’Halloran \& Lim, 2011), sedangkan di sisi lain literasi multimodal merupakan model pembelajaran mutakhir yang mengedepankan aktivitas peserta didik dalam setiap interaksi edukatif untuk dapat melakukan eksplorasi dan menemukan pengetahuannya sendiri (Nurhasnawati, 2012).

\section{B. Kompetensi Literasi Multimodal Mahasiswa}


Pada dasarnya pembelajaran sastra multimodal merupakan acuan pembelajaran berperspektif sosial-budaya dengan memerhatikan isi dan kualitas melalui multisemiotik teks sastra. Dalam perspektif sosial-budaya, pembelajaran dianggap sebagai tindakan sosial dan dimediasi melalui interaksi dan pemanfaatan berbagai sumber teks (Wertsch, 1998). Pengetahuan digunakan dalam proses pembelajaran sebagai sumber untuk memecahkan masalah dan mengelola situasi dengan tepat. Pembelajaran dan pengetahuan dianggap memiliki hubungan dan interaksi antara peserta didik, pendidik dan sumber teks yang muncul dalam proses pembelajaran dengan memerhatikan isi dan kualitas (Ryberg, 2008; Matsushita, 2018).

Melalui pembelajaran sastra multimodal diharapkan dapat memberikan kontribusi positif dalam meningkatkan kapabilitas mahasiswa di Perguruan Tinggi terutama di era revolusi industri 4.0 (abad 21), baik dalam persaingan antarbangsa maupun kemitraan dengan bangsa lain. Secara umum, pendidikan tinggi bertujuan: (a). berkembangnya potensi Mahasiswa agar menjadi manusia yang beriman dan bertakwa kepada Tuhan Yang Maha Esa dan berakhlak mulia, sehat, berilmu, cakap, kreatif, mandiri, terampil, kompeten, dan berbudaya untuk kepentingan bangsa; (b). dihasilkannya lulusan yang menguasai cabang ilmu pengetahuan dan/atau teknologi untuk memenuhi kepentingan nasional dan peningkatan daya saing bangsa; (c). dihasilkannya ilmu pengetahuan dan teknologi melalui penelitian yang memperhatikan dan menerapkan nilai humaniora agar bermanfaat bagi kemajuan bangsa, serta kemajuan peradaban dan kesejahteraan umat manusia; dan (d). terwujudnya pengabdian kepada masyarakat berbasis penalaran dan karya penelitian yang bermanfaat dalam memajukan kesejahteraan umum dan mencerdaskan kehidupan bangsa (Presiden Republik Indonesia, 2012). Secara khusus, disinggung tentang pembelajaran dalam UU Pendidikan Tinggi nomor 12 tahun 2012 pasal 13 ayat 1 dan 2, yakni: (1). mahasiswa sebagai anggota Sivitas Akademika diposisikan sebagai insan dewasa yang memiliki kesadaran sendiri dalam mengembangkan potensi diri di Perguruan Tinggi untuk menjadi intelektual, (2). Mahasiswa sebagaimana dimaksud pada ayat (1) secara aktif mengembangkan potensinya dengan melakukan pembelajaran, pencarian kebenaran ilmiah, dan/atau penguasaan, pengembangan, dan pengamalan suatu cabang Ilmu Pengetahuan dan/atau Teknologi untuk menjadi ilmuwan, intelektual, praktisi, dan/atau profesional yang berbudaya.

Tujuan dan hasil belajar pada pembelajaran sastra multimodal (Jewitt, 2008) yakni, (a). manajemen pembelajaran mandiri dan pemantauan pembelajaran sendiri, (b). perluasan pembelajaran sendiri, (c). pembelajaran kolaboratif proses kelompok efektif. 


\begin{tabular}{|c|c|c|}
\hline No & Tujuan & Hasil Belajar Peserta Didik \\
\hline 1 & $\begin{array}{l}\text { Manajemen pembelajaran mandiri dan } \\
\text { pemantauan pembelajaran sendiri }\end{array}$ & $\begin{array}{l}\text { Mampu memformulasikan pertanyaan } \\
\text { dan menghasilkan pertanyaan sendiri }\end{array}$ \\
\hline 2 & Perluasan pembelajaran sendiri, & $\begin{array}{l}\text { Mampu menerapkan pembelajaran } \\
\text { dalam konteks baru dan belajar di luar } \\
\text { kurikulum. }\end{array}$ \\
\hline 3 & $\begin{array}{l}\text { Pembelajaran kolaboratif proses } \\
\text { kelompok yang efektif }\end{array}$ & $\begin{array}{l}\text { Mampu interaktif menyumbangkan ide } \\
\text { mereka sendiri dengan jelas dan } \\
\text { mempertimbangkan sudut pandang } \\
\text { lain secara objektif dan matang }\end{array}$ \\
\hline
\end{tabular}

Proses pembelajaran sastra multimodal melibatkan mahasiswa dalam mempelajari teks multimodal. Sumber teks multimodal tersedia dalam bentuk bahasa dan gambar yang tersistem. Pengenalan pilihan sistem yang tersedia dalam proses pembelajaran dikenalkan kepada peseta didik untuk mengidentifikasi pilihan-pilihan dalam teks multimodal yang disajikan. Identifikasi tersebut untuk menjelaskan bagaimana pilihan-pilihan ini mengarah pada maknamakna tertentu yang dibuat. Terdapat tingkatan dalam proses pembelajaran ini, yakni (a) tingkatan dengan membubuhi teks dan analisis visual, dan (b) interpretasi melalui lembar kerja. Tingkatan pertama, membubuhi teks dan analisis visual dengan alat teknologi yang terdaftar. Alat yang lebih canggih, seperti Analisis Gambar Multimodal / Video, juga menyediakan opsi untuk analisis gambar. Tingkatan kedua, peserta didik didorong untuk mendukung interpretasi mereka terhadap teks-teks multimodal dengan mengutip bukti-bukti tekstual dari analisis mereka. Proses ini dicapai melalui lembar kerja yang dirancang dengan pertanyaan untuk mengarahkan peserta didik dari deskripsi tekstual ke analisis tekstual. Akhirnya, peserta didik diberi kesempatan untuk mengartikulasikan pandangan mereka dan mendiskusikan ideologi dalam teks multimodal dengan mengidentifikasi strategi yang digunakan untuk menarik kesimpulan. Peserta didik dapat diundang untuk mempresentasikan analisis mereka dan mempertahankan interpretasi mereka terhadap teks di kelas. 


\section{Strategi Pembelajaran Sastra Multimodal}

Strategi pembelajaran sastra multimodal mengacu pada strategi pembelajaran konstruktivisme project based learning yang selanjutnya dikembangkan sesuai dengan kebutuhan pembelajaran. Project-based learning merupakan strategi pembelajaran inovatif, yang menekankan belajar kontekstual melalui kegiatan-kegiatan yang kompleks (Cord, 2001; Thomas, Mergendoller, \& Michaelson, 1999; Moss, Van-Duzer, Carol, 1998). Project-based learning berfokus pada konsep-konsep dan prinsip-prinsip utama (central) dari suatu disiplin, melibatkan mahasiswa dalam kegiatan pemecahan masalah dan tugas-tugas bermakna lainya, memberi peluang mahasiswa bekerja secara otonom mengkonstruk belajar mereka sendiri, dan puncaknya menghasilkan produk karya mahasiswa bernilai, dan realistik (Okudan. Gul E. dan Sarah E. Rzasa, 2004). Strategi pembelajaran project-based learning lebih menekankan pada kegiatan belajar yang relatif berdurasi panjang, holistik-interdisipliner, perpusat pada pebelajar, dan terintegrasi dengan praktik dan isu-isu dunia nyata. Dalam project-based learning mahasiswa belajar dalam situasi problem yang nyata, yang dapat melahirkan pengetahuan yang bersifat permanen dan mengorganisir proyek-proyek dalam pembelajaran (Thomas, 2000).

Pembelajaran berbasis proyek adalah strategi pembelajaran efektif yang berfokus pada kreatifitas berfikir, pemecahan masalah, dan interaksi antara mahasiswa dengan kawan sebaya mereka untuk menciptakan dan menggunakan pengetahuan baru. Khususnya ini dilakukan dalam konteks pembelajaran aktif, dialog ilmiah dengan supervisor yang aktif sebagai peneliti (Berenfeld, 1996; Marchaim 2001; dan Asan, 2005). Berdasarkan pendapat-pendapat tersebut, project-based learning merupakan strategi pembelajaran yang dikembangkan berdasarkan faham pembelajaran konstruktivis yang menuntut peserta didik menyusun sendiri pengetahuannya (Doppelt, 2003).

Buck Institute for Education (1999) menyebutkan bahwa project-based learning memiliki karakteristik, yaitu: (a) mahasiswa sebagai pembuat keputusan, dan membuat kerangka kerja, (b) terdapat masalah yang pemecahannya tidak ditentukan sebelumnya, (c) mahasiswa sebagai perancang proses untuk mencapai hasil, (d) mahasiswa bertanggungjawab untuk mendapatkan dan mengelola informasi yang dikumpulkan, (e) melakukan evaluasi secara kontinu, (f) mahasiswa secara teratur melihat kembali apa yang mereka kerjakan, (g) hasil akhir berupa produk dan dievaluasi kualitasnya, dan (h) kelas memiliki atmosfer yang memberi toleransi kesalahan dan perubahan. 
Project-based learning memiliki potensi yang besar untuk membuat pengalaman belajar yang menarik dan bermakna bagi mahasiswa untuk memasuki lapangan kerja. Menurut Gaer (1998), di dalam project-based learning yang diterapkan untuk mengembangkan kompetensi setelah mahasiswa bekerja di perusahaan, mahasiswa menjadi lebih aktif di dalam belajar, dan banyak keterampilan yang berhasil dibangun dari proyek di dalam kelasnya, seperti keterampilan membangun tim, membuat keputusan kooperatif, pemecahan masalah kelompok, dan pengelolaan tim. Keterampilan-keterampilan tersebut besar nilainya ketika sudah memasuki lingkungan kerja. dan merupakan keterampilan yang sukar diajarkan melalui pembelajaran tradisional.

Memperhatikan karakteristiknya yang unik dan komprehensif, strategi pembelajaran berbasis proyek (Project-Based Learning) cukup potensial untuk memenuhi tuntutan pembelajaran Abad 21 (Era Rovolusi Industri 4.0). Strategi Pembelajaran Berbasis Proyek membantu mahasiswa dalam belajar: (1) pengetahuan dan keterampilan yang kokoh dan bermakna-guna (meaningful-use) yang dibangun melalui tugas-tugas dan pekerjaan yang otentik (Cord, 2001; Hung \& Wong, 2000; Myers \& Botti, 2000; Marzano, 1992); (2) memperluas pengetahuan melalui keotentikan kegiatan kurikuler yang terdukung oleh proses kegiatan belajar melakukan perencanaan (designing) atau investigasi yang open-ended, dengan hasil atau jawaban yang tidak ditetapkan sebelumnya oleh perspektif tertentu; dan (3) dalam proses membangun pengetahuan melalui pengalaman dunia nyata dan negosiasi kognitif antarpersonal yang berlangsung di dalam suasana kerja kolaboratif.

Langkah-langkah pembelajaran berbasis proyek, yakni: (a). Merancang dan menyiapkan perlengkapan untuk proyek, menentukan metode, tempat, dan gejala-gejala, (b). Pembentukan kelompok dan pemilihan proyek: mahasiswa diharapkan untuk memecahkan permasalahan yang dipilih secara jujur dalam kelompok kecil, (c). Pengumpulan informasi: presentasi ringkas dan diskusi proyek individual, yang mendukung pengumpulan berbagai pandangan atas proyek, (d). Langkah kerja proyek: langkah kerja merupakan bagian penting dari kerja kelompok. Adapun hal-hal yang dilihat berkaitan dengan bagaimana motivasi mahasiswa dalam mengikuti project-based learning, cara mahasiswa dalam melakukan problem-solving, proses kolaborasi antar mahasiswa dan dosen, serta kemandirian mahasiswa dalam menyelesaikan proyek-proyek.

Langkah ketiga adalah Evaluasi (interpretasi dan membuat perbandingan, menyimpulkan \& membuat laporan proyek). Hal-hal yang disiapkan dalam PBL: kurikulum, perelengkapan proyek, lingkungan fisik, lingkungan sosial, dan interaksi aspek-aspek tersebut. Pola ini menunjukan bentuk aktivitas dalam melakukan penilaian terhadap mahasiswa. 
Feedback membantu dosen dalam menafsirkan penguasaan mahasiswa tehadap proyek yang telah dikerjakannya.

\section{Daftar Rujukan}

Ausubel, D. P. 1963. The psychology of meaningful verbal learning.

Asan, A dan Haliloglu, Z. 2005. Implementing Project Based Learning In Computer Classroom. The Turkish Online Journal of Educational Technology - TOJET, volume 4 Issue 3. http://www.tojet.net/articles/ 4310.doc.Diakses 3-4-2008

Berenfeld B. 1996. Linking Students to the Info-sphere. Technology Horizon in Education Journal, 23, 76 - 84.

Coccetta, F. 2018. Developing university students ' multimodal communicative competence : Field research into multimodal text studies in English. System, 1-9. https://doi.org/10.1016/j.system.2018.01.004

Cord, 2001. Contextual Learning Resource. http://www.cord.org. Diakses 3 Desember 2006

Doppelt, Y. 2003. Implementation and assessment of project-basd learning in flexible environment. Instructional Journal of Technology and Design Education. Volume 13 Page 255-272.

Firmansyah, M. B. (2018, January 3). MODEL PEMBELAJARAN DISKUSI BERBASIS PERILAKU BERLITERASI UNTUK KETERAMPILAN BERBICARA_BAYU_sept_2017. Retrieved from osf.io/eacnf

Firmansyah, M. B. (2018, January 3).

KompetensiLiterasiMahasiswaDalamPembelajaranMatakuliahSeminarDiProdiPe ndidikanBahasaDanSastraIndonesia_Bayu. Retrieved from osf.io/n9xmp

Firmansyah, M. B. (2018). Model Pembelajaran Diskusi Berbasis Perilaku Berliterasi Untuk Keterampilan Berbicara. Jurnal Ilmiah Edukasi \& Sosial, 8(2), 119-125.

Firmansyah, M. B. (2018, January 3). Social and Political Values in Iwan Fals's Song Collections_bayu. Retrieved from osf.io/ayj8e

Firmansyah, M. B. (2018). Evaluasi Pembelajaran Bahasa Berbasis Lingkungan: Perspektif Pendekatan Pragmatik_Mochamad Bayu Firmansyah_STKIP PGRI Pasuruan.

Firmansyah, M. B. (2018). Pengembangan Profesionalitas Guru Bahasa Indonesia_M. Bayu Firmansyah_STKIP PGRI Pasuruan Jawa Timur Indonesia.

Firmansyah, M. B. PENINGKATAN KEMAMPUAN MENULIS PUISI DENGAN TEKNIK GEN ESTETIKA DAN PENGINTEGRASIAN STRATEGI METAKOGNITIF PADA SISWA KELAS VII MTS YTI NGULING TAHUN PELAJARAN 2013/2014.

Firmansyah, M. B. (2017). REPRESENTASI BAHASA HUMOR DALAM ACARA STAND UP COMEDY DI METRO TV. Jurnal Keilmuan Bahasa, Sastra, dan Pengajarannya, 2(2), 195-202. 
Firmansyah, B. (2018). Kompetensi Literasi Mahasiswa Dalam Pembelajaran Mata Kuliah Seminar Di Prodi Bahasa Dan Sastra Indonesia. Jurnal Ilmiah Edukasi \& Sosial, 8(1), 12-17.

Firmansyah, M. B. (2018). MULTIMODAL CONCEPTION IN LEARNING. ISLLAC: Journal of Intensive Studies on Language, Literature, Art, and Culture, 2(1), 4044.

Firmansyah, M. B. (2018). Dimensi Sosial dalam Novel Negeri Para Bedebah Karya Tere Liye (Perspektif Analisis Wacana Kritis). KEMBARA: Jurnal Keilmuan Bahasa, Sastra, dan Pengajarannya, 4(1).

Rokhmawan, T., \& Firmansyah, M. B. (2018). Budaya Lisan sebagai "Pembawa Nilai Normatif" Masyarakat Santri: Analisis Konten Didaktik dan Penyusunan Cergam Legenda Para Ulama.

Rokhmawan, T., \& Firmansyah, M. B. (2018, April 8). Budaya Lisan sebagai "Pembawa Nilai Normatif" Masyarakat Santri : Analisis Konten Didaktik dan Penyusunan Cergam Legenda Para Ulama. https://doi.org/10.31219/osf.io/rb3pu

Firmansyah, M. B., Rokhmawan, T., \& Pasuruan, S. P. (2018). Optimalisasi Kompetensi Komunikasi Multimodal Mahasiswa. INA-Rxiv. September, 4.

Firmansyah, M. B. (2018). LITERARY LEARNING CONTAIN CREATIVE ECONOMY. ISCE: Journal of Innovative Studies on Character and Education, 2(2), 321-331.

Firmansyah, M. B. (2018). Konseptualisasi Pembelajaran Sastra Digital. Jurnal Ilmiah Edukasi \& Sosial, 9(1), 21-27.

Firmansyah, M. B. (2018). KOMPETENSI LITERASI MULTIMODAL MAHASISWA: STUDI PUSTAKA TERHADAP TEKS MULTIMODAL BERMUATAN KEARIFAN LOKAL SERTA IMPLEMENTASINYA DALAM PEMBELAJARAN.

Rokhmawan, T., \& Firmansyah, B. (2015). Bangunan "Kerajaan Surgawi”: Kepercayaan Irasional dan Fungsi Sosial dalam Legenda Kiai Sepuh. Jurnal Ilmu-ilmu Humaniora, (1).

Firmansyah, M. B. (2019). Psychological Settings in Andrea Hirata's Laskar Pelangi_Nafisa_Firmansyah_2017.

Firmansyah, M. B. (2019). LITERASI MULTIMODAL BERMUATAN KEARIFAN LOKAL SERTA IMPLEMENTASINYA DALAM PEMBELAJARAN. Jurnal Ilmiah Edukasi \& Sosial, 10(1), 60-68.

Rokhmawan, T., \& Firmansyah, M. B. (2019). Kenapa Kita Harus Percaya Legenda Kiai?(Studi Kepercayaan Masyarakat Muslim terhadap Legenda Kiai Sepuh di Kota Pasuruan). Al-Makrifat: jurnal kajian Islam, 4(1), 1-42.

Firmansyah, M. B., SS, M. P., Tristan Rokhmawan, S. S., \& Pasuruan, S. P. Budaya Lisan sebagai "Pembawa Nilai Normatif" Masyarakat Santri: Analisis Konten Didaktik dan Penyusunan Cergam Legenda Para Ulama Oral Culture as a Santri's "carrier of norms": Analysis of Didactic Content and Arranging Pictorial Stories of The Legend 
of Ulama. HALAMAN COVER REDAKSIONAL DAFTAR ISI ARTIKEL PEMAKALAH UTAMA SASTRA LISAN BERBASIS INDUSTRI KREATIF: Ruang

Penyimpanan.

Firmansyah, M. B. (2019). LITERASI MULTIMODAL BERMUATAN KEARIFAN LOKAL SERTA IMPLEMENTASINYA DALAM PEMBELAJARAN. Jurnal Ilmiah Edukasi \& Sosial, 10(1), 60-68.

Firmansyah, M. B., \& Rokhmawan, T. (2019). PENGEMBANGAN KOMPETENSI KOMUNIKASI MULTIMODAL MAHASISWA STKIP PGRI PASURUAN. Jurnal Ilmiah Edukasi \& Sosial, 9(2), 124-133.

Firmansyah, M. B., Gay, M., \& Rasional, A. (2019). STRATEGI PEMBELAJARAN INKUIRI UNTUK MENGUKUR BUTIR TES. INA-Rxiv. October, 1.

Tristan Rokhmawan, S. S., Pasuruan, S. P., Firmansyah, M. B., \& SS, M. P. Bangunan "Kerajaan Surgawi": Kepercayaan Irasional dan Fungsi Sosial dalam Legenda Kyai.

Firmansyah, M. B., Siswanto, W., \& Roekhan, E. T. P. (2020). Multimodal Smartphone: Millennial Student Learning Style.

Freyn, A. L., \& Ed, D. 2017. Effects of a Multimodal Approach on ESL / EFL University Students 'Attitudes towards Poetry, 8(8), 80-83. Retrieved from ISSN 2222-1735 (Paper) ISSN 2222-288X (Online)

Gaer, S. 1998. What is Project-Based Learning?. http://members.aol.com

Halliday, M.A.K. 1977. Language as Social Semiotic: Towards as General Sociolinguistic Theory. Dalam Makkai, A., Makkai, V.B., \& Heilmann, L. (Eds.), Linguistics at the Crossroads (hlm. 13-41). Padova: Tipografia-La Garangola.

Halliday, M.A.K. 1978. Language as Social Semiotic: The Social Interpretation of Language and Meaning. London: Edward Arnold.

Halliday, M.A.K. 1985/1994. An Introduction to Functional Grammar. London: Edward Arnold Publishers Ltd.

Halliday, M.A.K. \& Hasan, R. 1992. Bahasa, Konteks, dan Teks: Aspek-Aspek Bahasa dalam Pandangan Semiotik Sosial. Terjemahan oleh Barori Tou. Yogyakarta: Gajah Mada University Press.

Hasan, R. \& Martin, J.R. Introduction. Dalam Hasan, R. \& Martin, J.R. (Eds.), 1989. Language Development: Learning Language, Learning Culture (Meaning and Choice in Language: Studies for Michael Halliday) (hlm. 1 17). Norwood-New Jersey: Ablex Publishing Corporation.

Halliday, M. A., \& Christian, M. I. M. 2004. Matthiessen. An introduction to functional grammar.

Hung, D.W., \& Wong, A.F.L. 2000. Activity Theory as a Framework fo Project Work in Learning Environments. Educational Technology, 40(2), 33-37.

Jewitt, C. 2008. Multimodality and Literacy in School Classrooms. Review of Research in 
Education, 32(1), 241-267. https://doi.org/10.3102/0091732X07310586

Jewitt, C., \& Kress, G. R. (Eds.). 2003. Multimodal literacy. New York: Lang.

Kennedy, V. 2014. Critical, cultural and multimodal approaches to using song as literature in language learning. Libri \& Liberi, 3(2), 295-310.

Lim-Fei, V., \& Yin, S. T. K. 2017. Multimodal Translational Research: Teaching Visual Texts. New Studies in Multimodality: Conceptual and Methodological Elaborations, 175.

Marzano, R.J. 1992. A Different Kind of Classroom: Teaching with Dimensions of Learning. Verginia: ASCD.

Marchaim, U. 2001. High-school Student Research at Migal Science Institute in Israel. Journal of Biological Education, 35(4), 178

Matsushita, K. 2018. Deep Active Learning. https://doi.org/10.1007/978-981-10-5660-4

Myers, R.J., \& Botti, J.A. 2000. Exploring the Environment: Problem-Based Learning in Action. http: www.cet.edu/research/conference.html.

Nasir, M. 2018. Pendidikan Tinggi Berkualitas:“Mendorong Kemajuan IPTEK, Inovasi, dan Daya Saing Bangsa di Era Revolusi Industri 4.0”.

Nurhasnawati. 2012. Model-model pembelajaran. PT Rajagrafindo Persada, 237-259.

Okudan. Gul E. dan Sarah E. Rzasa. 2004. A Project-Based Approach to Entreprenurial Leadership Education. Journal Technovation. Desember. Volume XX. Page 1-16.

Presiden Republik Indonesia. 2012. Undang-Undang Republik Indonesia Nomor 12 Tahun 2012 tentang Pendidikan Tinggi. Undang-Undang PENDIDIKAN TINGGI, 1-97. https://doi.org/10.1073/pnas.0703993104

Piaget, J. 2013. The moral judgment of the child. Routledge.

Ryberg, T., \& Christiansen, E. 2008. Community and social network sites as technology enhanced learning environments. Technology, Pedagogy and Education, 17(3), 207-219.

Suparno, P. 1997. Filsafat konstruktivisme dalam pendidikan.

Tinggi, D. J. P. 2014. Buku panduan Pengembangan Kurikulum Pendidikan Tinggi Berbasis Kompetensi Pendidikan Tinggi yang merujuk pada SN-DIKTI dan KKNI. Dijen Dikti. Kemendikbud. Jakarta.

Thomas, J.W., Margendoller, J.R., \& Michaelson, A. 1999. Project-Based Learning: A. Handbook for Middle and High School Teachers. http://www.bgsu.edu/organizations/ctl/proj.html.

Thomas, J. W. 2000. A review of research on project-based learning. Retrieved 18 July 2005 from http://www.autodesk.com/foundation

Wadsworth, B. J. 1996. Piaget's theory of cognitive and affective development: Foundations of constructivism. Longman Publishing.

Wertsch, J. V. 1998. Mind as action. 
